\title{
IAMJ
}

INTERNATIONAL

AYURVEDIC

MEDICAL JOURNAL

ISSN: 2320-5091

Impact Factor: 6.719

\section{ROLE OF NUTRITION AND LIFESTYLE CHANGES FOR CANCER RISK IN INDIA}

\section{Pawar Sarika Shivaji}

Assistant Professor Dept. of Kriya Sharir,

N K Jabshetty Ayurvedic Medical College and P G Centre, Bidar - 585401, Karnataka, India

Corresponding Author: drsarikapawar@yahoo.com

https://doi.org/10.46607/iamj07p5042021

(Published online: May 2021)

Open Access

(C) International Ayurvedic Medical Journal, India 2021

Article Received: 31/03/2021 - Peer Reviewed: 07/05/2021 - Accepted for Publication: 08/05/2021

Check for updates

\begin{abstract}
India is a developing country with one of the most diverse population and diet in the world. Cancer rates in India are lower than those seen in Western countries but are rising with increasing migration of rural population to the cities, increase in life expectancy and changes in lifestyles. In India, rates for oral and oesophageal cancer are some of the highest in the world. In contrast, the rates for colorectal, prostate, and lung cancers are one of the lowest. Studies of Indian immigrants in Western societies indicate that rates of cancer and other chronic diseases such as coronary heart disease and diabetes increase dramatically after a generation in the adopted country. Change of diet is among the factors that may be responsible for the changing disease rate. In prevention of cancer in India attention being focused on certain aspects of Indian diet such as vegetarianism, spices, and food additives such as turmeric. Researcher also has investigated cumin, chillies, kalakhar, Amrita Bindu and various plant seeds for their apparent cancer preventive properties. From a public health perspective, there is an increasing need to develop cancer prevention programs responsive to the unique diet and cultural practices of the people of India.
\end{abstract}

Keywords: India, Cancer, Prevention, Diet. 


\section{INTRODUCTION}

The relationship between diet and health has been recognized throughout recorded history. Disease prevention through healthy preparation of foods and eating habits has been discussed in religious and civil writings for thousands of years ${ }^{1}$. Since the 19th century, western scientific methodologies have been applied to the study of diet and disease with the intent of reducing the disease burden from non-communicable diseases (NCD) such as cancer, coronary heart disease (CHD), and other conditions endemic to societies after the advent of industrialization. Ecologic, observational, and laboratory studies generally agree that eating a diet high in vegetables, fruits, and other plant-based foods; low in animal fats and low in salt content, along with maintaining a healthy weight, not using tobacco in any form, and being physically active can reduce the risk of cancer, $\mathrm{CHD}$, and other chronic diseases ${ }^{2,3}$. Diet-related NCDs are of great concern to researchers assessing the impact of changes in diet in "developing" countries, such as India. Trends, based on current and projected data, in nutritional and disease status indicate that these countries face considerable challenges as under-nutrition evolves into overnutrition as the community becomes "developed"4.

Dietary customs and habits in India are diverse, owing in part, to the range of religions in the society, many of which provide specific dietary guidance for their followers ${ }^{\mathbf{1}}$. Furthermore, there is a tradition of linking vegetarianism with medicine. For example, Ayurveda provides dietary guidance and proscriptions that have been developed over millennia to prevent and treat multiple ailments, including CHD, cancer, and diabetes. Cancer rates in India are rising as development progresses, with a changing profile of burden at different cancer sites. According to the World Health Organization (WHO), cancer rates in India are considerably lower than those in more developed countries such as the United States ${ }^{5}$. Data from populationbased cancer registries in India show that the most frequently reported cancer sites in males are lung, oesophagus, stomach, and larynx. In females, cancers of the cervix, breast, ovary, and oesophagus are the most commonly encountered ${ }^{6}$.
Contrary to what is seen in most developing countries, India has some of the highest CHD rates in the world ${ }^{\mathbf{1}}$, with urban rates being three times higher than rural rates ${ }^{7}$. In addition, rates for obesity and diabetes are increasing dramatically in urban areas and in highincome rural residents ${ }^{4,7}$. For example, the prevalence of diabetes in urban areas has been reported at 9-16\%, more than four times the prevalence of two decades $\mathrm{ago}^{8}$. Diet appears to be related to the high rates of CHD, obesity, and diabetes, although a genetic component may exist in some cases. In recent decades, consumption of food grains also has shifted from coarse grains (e.g., barley, rye, maize, millet, and sorghum) to refined rice and wheat ${ }^{4}$.

Studies of immigrants provide insight into the contributions of environmental, behavioural, genetic, and lifestyle factors that determine risks for chronic diseases in Indians. Various immigration studies have included Asian Indians. Trends for cervical cancer incidence were investigated in a population-based study using 1968-1987 data from the Singapore Cancer Registry ${ }^{9}$. Incidence rates were highest in women from India, followed by China and Malaysia. Data from 1968-1982 remained the same when compared in 5-year periods, although rates declined in each group 9. Data from the National Cancer Registry of Malaysia from 1987-1989 showed that site-specific cancers differ among Malays (larynx and oesophagus), Chinese (nasopharyngeal), and Indians (mouth cancers), and that Malaysia is in a cancer-transitional state from less industrialized (frequent sites: stomach, cervix, lung) to industrialized (frequent sites: lung, breast, rectum) ${ }^{\mathbf{1 0}}$. The NUSHS (National University of Singapore Heart Study) assessed dietary factors to determine the impact of diet on increasing rates of CHD, cerebrovascular disease, and cancer, and found vitamin $\mathrm{C}$ levels were lower in Malays and Asian Indians, which may have been responsible for higher CHD and cancer rates in those groups ${ }^{\mathbf{1 1}}$.The authors suggest that a low intake of fresh fruits and high cooking temperatures in Malay and Asian Indian dishes may account for the low levels of vitamin C. Recent case-control studies in Asian Indian immigrants in the United Kingdom and 
the United States identified high levels of homocysteine as a risk factor for the development of CHD 12,13 and cancer ${ }^{14}$.

\section{REVIEW OF LITERATURE:}

\section{Dietary Factors and Lifestyle:}

In India dietary changes, reductions in physical activity and increasing obesity has been associated with the risk of chronic disease, although few of these associations have been investigated into or quantified adequately. Though not a comprehensive review, the following sections discuss factors of diet and lifestyle that may contribute to the growing burden of chronic diseases in India

Obesity and Physical Activity:

Obesity and lack of physical activity are associated with increased risk at various cancer sites, including breast and endometrial cancer ${ }^{2}$. Energy balance, which includes maintaining ideal weight through physical exercise, has been associated with decreased risk of breast cancer ${ }^{2}$.

Vegetarian Diets: A large percentage of Indians, particularly Hindus, practice vegetarianism and avoid meat and fish products in their diet. Vegetarian diets have been associated with decreased risk for prostate cancer ${ }^{15}$. Case-control studies that compared nonvegetarian and vegetarian diets and alcohol and tobacco use in India have reported that vegetarians have a reduced risk of oral ${ }^{15}$, Oesophageal ${ }^{\mathbf{1 6}}$, and breast cancers ${ }^{17}$. Vegetarian diets rely on pulses (e.g., beans, chickpeas, and lentils) as a source of protein, and pulses have been significantly associated with reductions in cancer ${ }^{17,18}$.

Dietary Fats and Fiber: Diets high in saturated fats have been associated with increased risk for cancer ${ }^{2}$. Large epidemiological studies have identified a possible association between increased dietary fiber and a decreased risk for cancers of the colon and breast ${ }^{2}$.The Indian diet, which generally includes adequate levels of vegetables, fruits, and fiber-rich grains, may provide some protection against increased risk for these cancers ${ }^{2}$.
Spices and Food Additives: Diet in India developed over thousands of years and is based on a mix of religious and secular beliefs. In a study in human blood cancer cell lines, turmeric suppressed and destroyed blood cancer cells ${ }^{19}$. Turmeric has been shown to suppress tumour initiation, promotion, and metastasis in experimental studies ${ }^{19}$. To illustrate, turmeric may block the activity of nuclear factor kappa-B (NfkB), which, in an activated state, appears to be associated with cancer cell growth in many cell types ${ }^{19}$. Turmer$i c$ also has been found to inhibit the growth of 19 clinical strains of Helicobacter pylori, a carcinogenic bacterium linked to the increased risk of adenocarcinoma of the stomach and colorectal adenomas ${ }^{\mathbf{2 0}}$.

Amrita Bindu, a dietary supplement that is a saltspice-herbal mixture, was found to protect rats against cancer induced by N-methyl-N-nitrosoguanidine, a potent carcinogenic nitrosamine ${ }^{21}$. A recent study investigated the anti-carcinogenic effects of nine Indian spices on induction by dietary benzo[a] pyrene $(\mathrm{B}[\mathrm{a}] \mathrm{P})$ of squamous cell carcinomas (SCC) of the stomach in mice and induction by dietary 3'-methyl-4dimethylaminoazobenzene of hepatomas in rats ${ }^{22}$. Cumin seeds and basil leaves significantly decreased the incidence of both SCC and hepatomas; poppy seeds significantly inhibited B[a]P-induced SCC; and the other six spices showed no effect ${ }^{22}$.

Micronutrients: Micronutrients play a significant role in maintaining health and preventing disease, including cancer, through a wide range of mechanisms: anti-oxidation, anti-proliferation, and repair of DNA damage ${ }^{2}$. Direct and indirect relationships between micronutrients and health have been described in experimental, epidemiological and clinical trials ${ }^{2}$. Vitamin deficiencies, specifically of vitamins A, C and E, may contribute to the high prevalence of oral cancers in India ${ }^{23}$. Micronutrient deficiencies of iodine, iron, and vitamin A are highly prevalent in Indian children. Among 6-14-year-olds, goiter, caused by iodine deficiency and related to thyroid cancer, has a prevalence rate of 0.33 to $2.4 \%{ }^{24}$. 


\section{CANCER SITES:}

Oral Cancers: Incidence rates for oral cancer in India are among the highest in the world ${ }^{\mathbf{5}}$. Most are associated with diet, weight, and other lifestyle factors ${ }^{23}$. A significant lifestyle risk factor is betel quid (paan) chewing, a practice that is highly prevalent in India. A case-control study in Southern India investigated the influence of paan, body mass index (BMI), diet, infections, and sexual practices on oral cancer ${ }^{25}$. Frequent consumption of fish, eggs, a variety of raw and cooked vegetables, and fruit was associated with a decreased risk of oral cancer ${ }^{25}$. A study on reverse smoking (i.e. smoking with the glowing end inside the mouth) revealed that use of tobacco in this form conferred a 5.19 times higher risk of oral pre-cancerous lesions of the palate than did use of chewing tobacco 26. Diets low in vegetables and fruits and high in alcohol increase the risk of oral cancers ${ }^{2}$.

Oesophageal Cancer: In India, the incidence of oesophageal cancer is moderately high and is associated with certain diets and lifestyles. Among risk factors for oesophageal cancer in India, betel quid chewing carries a relative risk of 1.5 to 3.5. Use of kalakhar greatly increased the risk $(\mathrm{OR}=8.0)$ of oesophageal cancer ${ }^{27}$. In the same study, spicy foods $(\mathrm{OR}=5.1)$ and chilies $(\mathrm{OR}=6.9)$ also resulted in a significantly increased risk. Another case-control study found alcohol ( $\mathrm{OR}=7.81$ with daily use), chewing betel leaf with tobacco $(\mathrm{OR}=3.16)$, bidi smoking $(\mathrm{OR}=1.95)$, and a diet low in vegetable consumption $(\mathrm{OR}=1.88)$ to be risk factors for oesophageal cancer ${ }^{28}$.

\section{Endometrial, Cervical, and Ovarian Cancers:}

Cancer of the female reproductive tract has a high incidence amongst Indian women. Human papilloma virus (HPV) is the most prevalent risk factor for cervical cancer and has been associated with cancer of the ovaries and endometrium ${ }^{29}$. Some of the studies have suggested that a diet high in carotenoids, vegetables, and fruits may reduce the risk of cervical, ovarian, and endometrial cancers; high intake of vitamins $\mathrm{C}$ and $\mathrm{E}$ may reduce the risk of cervical cancer; and a diet high in fish may reduce the risk of ovarian cancer ${ }^{2}$.

Breast Cancer: In India, the incidence of breast cancer is increasing, with an estimated 80,000 new cases diagnosed annually. The nutrition guidelines follow the World Cancer Research Fund recommendations that advocate having a diet containing vegetables and fruits in large amounts, reducing the intake of saturated fats, and increasing physical activity ${ }^{2}$.

Stomach Cancer: Compared to other countries, stomach cancer incidence rates are moderate to low in India $^{6}$. A recent case-control study in Mumbai found that consumption of dried fish $(\mathrm{OR}=12.4)$ increased the risk while green tea consumption $(\mathrm{OR}=0.4)$ decreased the risk of having stomach cancer ${ }^{30}$. A prospective case-control study from Trivandrum evaluated dietary risk factors for stomach cancer and found that high consumption of rice $(\mathrm{OR}=3.9)$, spicy food $(\mathrm{OR}=2.3)$, chili $(\mathrm{OR}=7.4)$, and high-temperature food $(\mathrm{OR}=7.0)$ increased the risk of developing stomach cancer ${ }^{31}$. Fried foods are associated with higher rates of cancer due in part to the production of carcinogenic or mutagenic heterocyclic amines (HA) during the cooking process ${ }^{2}$. As mentioned earlier, the use of the spice turmeric is associated with a reduced risk of stomach cancer, in part because of its protective effect against the carcinogenic bacterium $\mathrm{H}$. pylori, a major risk factor for stomach cancer ${ }^{23}$.

\section{DISCUSSION}

There is extensive evidence suggesting that regular physical exercise may reduce the incidence of various cancers. A sedentary lifestyle has been associated with most chronic illnesses. Physical inactivity has been linked with increased risk of cancer of the breast, colon, prostate, and pancreas and of melanoma. The increased risk of breast cancer among sedentary women that has been shown to be due to lack of exercise has been associated with a higher serum concentration of estradiol, lower concentration of hormone-binding globulin, larger fat masses, and higher serum insulin levels. Physical inactivity can also increase the risk of colon cancer (most likely because of an increase in GI transit time, thereby increasing the duration of contact with potential carcinogens), increase the circulating levels of insulin (promote proliferation of colonic epithelial cells), alter prostaglandin levels, depress the immune function, and modify bile acid metabolism. 
Additionally, men with a low level of physical activity and women with a larger body mass index were more likely to have a Ki-ras mutation in their tumors, which occurs in 30-50\% of colon cancers. A reduction of almost $50 \%$ in the incidence of colon cancer was observed among those with the highest levels of physical activity. Similarly, higher blood testosterone and IGF1 levels and suppressed immunity due to lack of exercise may increase the incidence of prostate cancer. More than 25,000 different phytochemicals have been identified in fruits and vegetables that may have potential against various cancers. These phytochemicals have advantages because they are safe and usually target multiple cell-signaling pathways. Major chemo preventive compounds identified from fruits and vegetables include carotenoids, vitamins, resveratrol, quercetin, silymarin, sulphoraphane and indole-3-carbinol. Fruits and vegetables are the primary dietary sources of vitamins except for vitamin D. Vitamins, especially vitamins $\mathrm{C}, \mathrm{D}$, and $\mathrm{E}$, are reported to have cancer chemo preventive activity without apparent toxicity. The major wholegrain foods are wheat, rice, and maize; the minor ones are barley, sorghum, millet, rye, and oats contain chemo preventive antioxidants such as vitamin E, tocotrienols, phenolic acids, lignans, and phytic acid.

\section{CONCLUSION}

Diet is an important factor in cancer aetiology and prevention in India. As a society, Indians have one of the most interesting diets, with many unique dietary constituents that have promise for cancer prevention. Very few well-designed, prospective epidemiological research studies exploring the relationships between diet and lifestyle and cancer have been carried out in India.

Additional research is needed to assess the impact of diverse dietary habits, religious practices, and lifestyles on prevention of cancer. Cancer detection and prevention efforts can have enormous benefits for developing countries by reducing future disease burden while saving economic resources for needed improvements in societal infrastructure. As development and mechanization continue into the 21 st century, In- dia must grapple with a transition from the burden of communicable diseases to the burden of NCDs.

\section{REFERENCES}

1. Ahmed S. Coronary heart disease: the Indian Asian diet. Nurs Stand 1999; 13:45-7

2. World Cancer Research Fund, American Institute for Cancer Research. Food, nutrition, and the prevention of cancer: a global perspective / World Cancer Research Fund, in association with American Institute for Cancer Research. Washington, DC: American Institute for Cancer Research, 1997.

3. Schaefer EJ. Lipoproteins, nutrition, and heart disease. Am J Clin Nutr 2002; 75:191-212

4. Popkin BM, Horton S, Kim S, Mahal A, Shuigao J. Trends in diet, nutritional status, and diet-related noncommunicable diseases in China and India: the economic costs of the nutrition transition. Nutr Rev 2001; 59:379-90.

5. Fenley J, Bray F, Pisani DMe. World Health Organization. GLOBOCAN 2000: Cancer incidence, mortality and prevalence worldwide. Lyon, France: IARC Press; 2001.

6. Gajalakshmi V, Swaminathan R, Shanta V. An Independent Survey to Assess Completeness of Registration: Population Based Cancer Registry, Chennai, India. Asian Pac J Cancer Prev 2001; 2:179-83.

7. Gopalan C. Rising incidence of obesity, coronary heart disease and diabetes in the Indian urban middle class. Possible role of genetic and environmental factors. World Rev Nutr Diet 2001; 90:127-43.

8. Pradeepa R, Deepa R, Mohan V. Epidemiology of diabetes in India-current perspective and future projections. J Indian Med Assoc 2002; 100:144-48.

9. Seow A, Chia KS, Lee HP. Cervical cancer: trends in incidence and mortality in Singapore 1968 to 1987. Ann Acad Med Singapore 1992; 21:328-33.

10. Chan CK, Singh J, Rasid BK, Devaraj T. Penang cancer cases reported to the National Cancer Registry of Malaysia, 1987-1990: an epidemiological analysis. Med J Malaysia 1994; 49:122-31.

11. Hughes K, New AL, Lee BL, Ong CN. Plasma vitamins $\mathrm{A}, \mathrm{C}$ and $\mathrm{E}$ in the general population of Singapore, 1993 to 1995. Ann Acad Med Singapore 1998; 27:149-53.

12. Chambers JC, Wander GS, Kooner JS. Homocysteine and coronary heart disease amongst Indian Asians. Indian Heart J 2000; 52: S5-8. 
13. Chandalia M, Abate N, Cabo-Chan AV Jr, Devaraj S, Jialal I, Grundy SM. Hyperhomocysteinemia in Asian Indians living in the United States. J Clin Endocrinol Metab 2003; 88:1089-95.

14. Wu LL, Wu JT. Hyperhomocysteinemia is a risk factor for cancer and a new potential tumor marker. Clin Chim Acta 2002; 322:21-28.

15. Rajaram S, Sabate J. Health benefits of a vegetarian diet. Nutrition 2000; 16:531-33.

16. Rao DN, Ganesh B, Rao RS, Desai PB. Risk assessment of tobacco, alcohol and diet in oral cancer-a casecontrol study. Int J Cancer 1994; 58:469-73.

17. Rao DN. Role of vegetarian diet in cancers of the oesophagus and female breast in India. Vegetarian Congress Research Presentations, Section I: Diet and Chronic Disease. Loma Linda University Press; 1997. pp. 4, 2003.

18. Jain MG, Hislop GT, Howe GR, Ghadirian P. Plant foods, antioxidants, and prostate cancer risk: findings from case-control studies in Canada. Nutr Cancer 1999; 34:173-84.

19. Mills PK, Beeson WL, Phillips RL, Fraser GE. Cohort study of diet, lifestyle, and prostate cancer in Adventist men. Cancer 1989; 64:598-604.

20. Aggarwal BB, Kumar A, Bharti AC. Anticancer potential of curcumin: preclinical and clinical studies. Anticancer Res 2003; 23:363-98.

21. Mahady GB, Pendland SL, Yun G, Lu ZZ. Turmeric (Curcuma longa) and curcumin inhibit the growth of Helicobacter pylori, a group 1 carcinogen. Anticancer Res 2002; 22:4179-81.

22. Shanmugasundaram KR, Ramanujam S, Shanmugasundaram ER. Amrita Bindu-a salt-spice-herbal health food supplement for the prevention of nitrosamine induced depletion of antioxidants. J Ethnopharmacol 1994; 42:83-93.

23. Aruna K, Sivaramakrishnan VM. Anticarcinogenic effects of some Indian plant products. Food Chem Toxicol 1992; 30:953-56.

24. Tandon M, Kapil U, Bahadur S, Dwivedi SN, Pathak P. Role of micro-nutrients and trace elements in carcinoma of larynx. J Assoc Physicians India 2000; 48:995-98.

25. Chakravarty I, Ghosh K. Micronutrient malnutritionpresent status and future remedies. J Indian Med Assoc 2000; 98:539-42.

26. Rajkumar T, Sridhar H, Balaram P, Vaccarella S, Gajalakshmi V, Nandakumar A et al. Oral cancer in Southern India: the influence of body size, diet, infections and sexual practices. Eur J Cancer Prev 2003; 12:13543.

27. Phukan RK, Chetia CK, Ali MS, Mahanta J. Role of dietary habits in the development of esophageal cancer in Assam, the north-eastern region of India. Nutr Cancer 2001; 39:204-9.

28. Nayar D, Kapil U, Joshi YK, Sundaram KR, Srivastava SP, Shukla NK, et al. Nutritional risk factors in esophageal cancer. J Assoc Physicians India 2000; 48:78187.

29. Hisada M, van den Berg BJ, Strickler HD, Christianson RE, Wright WE, Waters DJ et al. Prospective study of antibody to human papilloma virus type 16 and risk of cervical, endometrial, and ovarian cancers (United States). Cancer Causes Control 2001:12:335-41.

30. Rao DN, Ganesh B, Dinshaw KA, Mohandas KM. A case-control study of stomach cancer in Mumbai, India. Int J Cancer 2002; 99:727-31.

31. Mathew A, Gangadharan P, Varghese C, Nair MK. Diet and stomach cancer: a case-control study in South India. Eur J Cancer Prev 2000; 9:89-97.

\section{Source of Support: Nil \\ Conflict of Interest: None Declared}

How to cite this URL: Pawar Sarika Shivaji: Role of Nutrition And Lifestyle Changes For Cancer Risk In India. International Ayurvedic Medical Journal \{online\} 2021 \{cited May, 2021\} Available from: http://www.iamj.in/posts/images/upload/2913_2918.pdf 